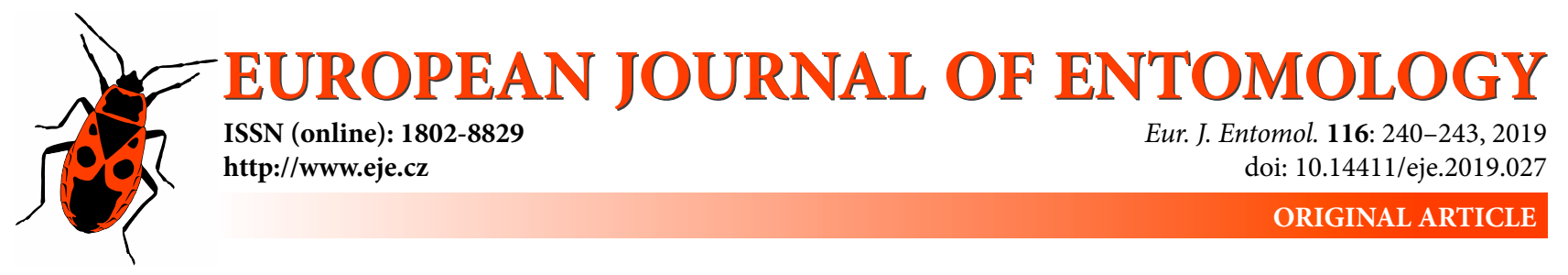

\title{
Yellow does not improve the efficiency of traps for capturing wasps of the genera Vespula and Dolichovespula (Hymenoptera: Vespidae)
}

\author{
JoUNI SORVARI
}

Department of Environmental and Biological Sciences, University of Eastern Finland, P.O. Box 1627, FI-70211 Kuopio, Finland; e-mail: jouni.sorvari@uef.fi

Key words. Hymenoptera, Vespidae, Vespula, Dolichovespula, monitoring, pest control, trap, colour, yellowjackets

\begin{abstract}
Social wasps are often considered as nuisance pests in urban environments and are often controlled by using traps. The majority of commercially produced traps for catching wasps have yellow as the dominant colour around the trap entrance. However, the observations on the function of yellow as an attractant for wasps are controversial. The efficiency of yellow, compared with green striped $(\mathrm{N}=15)$ and yellow and green striped beer traps $(\mathrm{N}=15)$ was evaluated. According to the results, yellow does not have a specific role as an attractant for wasps of the genera Vespula Linnaeus and Dolichovespula (Rohwer). For wasps, it may be the bait that is the major lure and it might be sufficient on its own for both control and monitoring purposes.
\end{abstract}

\section{INTRODUCTION}

Social wasps are often nuisance pests in urban environments and their sting can cause a serious allergic reaction (Rust \& Su, 2012). Sometimes they disrupt berry and fruit production and beekeeping (see Bacandritsos et al., 2006). Some species of wasps have been introduced outside their normal range and consequently have disturbed both the local ecosystem and humans (Beggs et al., 2011). Therefore, various types of wasp traps have been developed. The dominant colour around the entrance or other parts of the majority of commercially produced wasp traps is yellow. This is also confirmed by searching the Internet for photographs using the keywords wasp trap or yellowjacket trap.

Both of these traps have been successfully used for scientific monitoring purposes. A wide array of baits, such as beer, sugar and fermented fruit (Dvořák \& Landolt, 2006; Dvořák, 2007); protein-based baits (fish, mussels, meat; Chang, 1988; Bacandritsos et al., 2006; Unelius et al., 2014) and chemical attractants (acetic acid, heptyl butyrate, isobutanol, 2-methyl-2-propanol; Landolt et al., 2005, 2007) have been successfully used to trap wasps. An old study indicates a preference for yellow (Sharp \& James, 1979); however, it was based on a low number of replicates and lacked statistical rigour. Furthermore, a more recent study by Demichelis et al. (2014) did not find any significant preference of wasps for yellow traps over white traps. Since these results are controversial in terms of the effectiveness of the colour yellow in attracting wasps and the fact that most commercial wasp traps are coloured yellow, there is a need to evaluate the effectiveness of yellow in increasing the attractiveness of wasp traps.

The aim of this study is to evaluate the wasp trapping efficiency of beer traps that either have yellow and green marking or only green marking as an additional visual attractant.

\section{MATERIALS AND METHODS}

This study was carried out in Kuopio in central Finland (WGS84 $62^{\circ} 50^{\prime} \mathrm{N}, 27^{\circ} 38^{\prime} \mathrm{E}$ ). Traps were made from 0.51 transparent plastic beer glasses with a $6 \mathrm{~cm}$ wide and $1.5 \mathrm{~cm}$ high horizontal opening at the top and either two stripes of green or one green and one yellow stripe made of PVC electrician's tape (Fig. 1). The bait in the traps was 0.21 lager beer with brown sugar and yeast. (For the recipe, see Sorvari, 2013.) Yellow and green stripes were used on half of the traps instead of only yellow, since most commercial traps are coloured both yellow and green. While not tested, the transparency of traps may increase trapping efficiency, since the entrance is harder to find visually.

Fifteen pairs of green, and yellow and green traps, were set along the edges of forest. The pairs of traps were hung on trees at a maximum distance of two metres between the green and yellow and green traps in each pair. The traps were set at the same height and in similarly shaded situations. The height of the traps varied between 3 and $5 \mathrm{~m}$. The openings in the traps were set facing the most open landscape. The fifteen pairs of traps were distributed along three transects, each with five pairs of traps. The distance between pairs of traps along transects was approximately $50 \mathrm{~m}$. The midpoints of the transects were $450-850 \mathrm{~m}$ apart. The traps were set in the field for 21 days (7-28 August 2016) and were emptied on $14^{\text {th }}, 21^{\text {st }}$ and $28^{\text {th }}$ August (henceforth referred to as Week 1, Week 2 and Week 3). The traps were refilled with fresh 


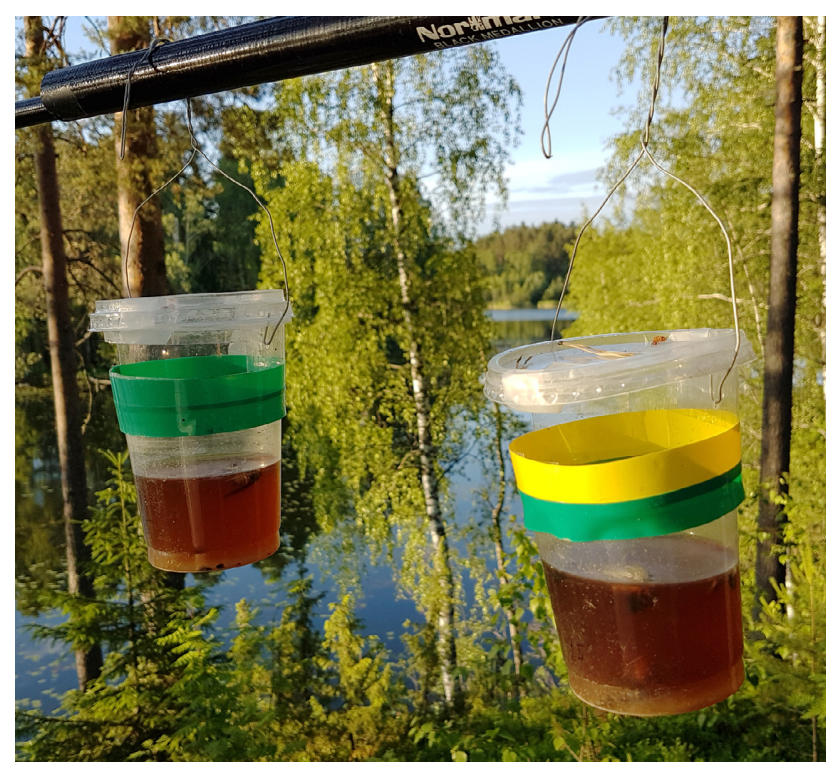

Fig. 1. Photograph of the green (left), and yellow and green (right) striped beer traps.

bait between weeks 1 and 2 and between weeks 2 and 3, i.e., on the $14^{\text {th }}$ and $21^{\text {st }}$ August 2016. The wasps caught were stored in $70 \%$ ethanol and later identified using the keys of Dvořák \& Roberts (2006) and Witt (2009).

A Pearson's correlation test was used to determine the correlation between green and yellow and green traps for each of the pairs. The number of wasps and different species of wasps in the traps were analysed using a generalized linear mixed model with Poisson distribution and a log link function. The trap-pair identity was used as a random factor with a Kenward-Roger 2 calculation for the correct estimation of the degrees of freedom in a model where a random variable is included. The numbers of wasps caught by the traps during the three-week periods were analysed using a repeated generalized linear mixed model with Poisson distribution and a log link function. The trap-pair identity was used as a repeat factor with a Kenward-Roger 2 calculation for the degrees of freedom. The analyses were carried out using the GLIMMIX procedure in SAS 9.4 statistical software. All estimated means are presented with $95 \%$ confidence intervals (EMM $\pm 95 \% \mathrm{CI})$.

\section{RESULTS}

A total of 605 wasps were caught by the traps, which belonged to the following six species: the common wasp Vespula vulgaris Linnaeus, red wasp V. rufa (Linnaeus), median wasp Dolichovespula media (Retzius), Saxon wasp D. saxonica (Fabricius), Norwegian wasp D. norwegica

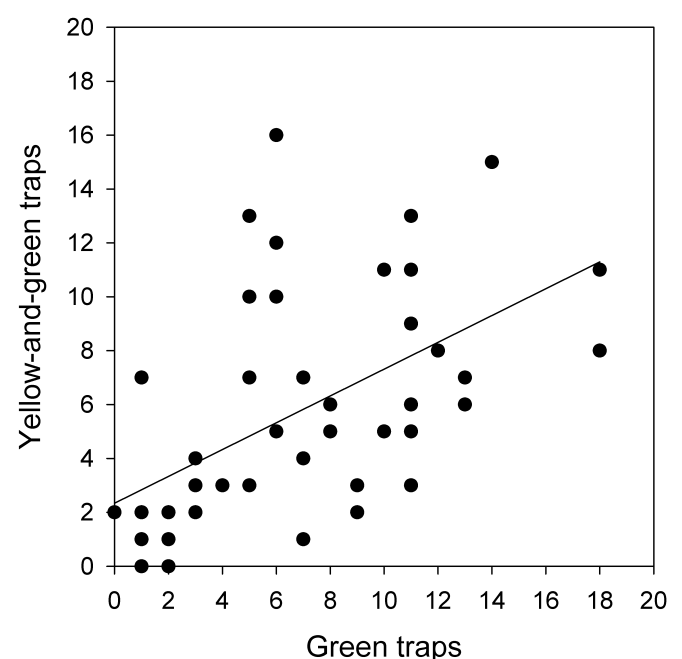

Fig. 2. The relationship between the numbers of $V$. vulgaris wasps caught by the green and yellow and green traps in each pair of traps. The equation of the linear relationship is $y=2.339+0.497 x$ $\left(r^{2}=0.30\right)$.

(Fabricius) and tree wasp D. sylvestris Scopoli (Table 1). By far the most common species was the common wasp, $V$. vulgaris, which made up $91.9 \%$ of the catch.

To determine if there is any bias due to the congeneric attraction of traps a correlation test of the numbers of wasps caught by pairs of traps was carried out. There was a significant correlation between the number of wasps caught in pairs of traps for $V$. vulgaris, which was the most abundant species $(\mathrm{N}=45, r=0.551, \mathrm{P}<0.001$; Fig. 2). Generally more wasps were caught by green traps, but some of the yellow and green traps clearly caught more wasps (Fig. 2 ). This may indicate some level of congeneric attraction. The total number of wasps (Vespula spp. + Dolichovespula spp.) caught by green traps was 1.22 times higher than by yellow and green traps. However, the number of wasps did not differ statistically $\left(F_{1,21.57}=1.76, P=0.20\right)$ (Fig. 3). The number of $V$. vulgaris and $D$. media caught did not differ significantly between green and yellow and green traps $\left(V\right.$. vulgaris: $F_{1,21.88}=1.02, P=0.32 ; D$. media: $F_{1,28}$ $=0.04, P=0.84$ (Fig. 3). Interestingly, the number of $D$. saxonica caught per green trap was 4.7 times higher than per yellow and green trap $\left(F_{1,28}=5.86, P=0.022\right.$; Fig. 3$)$. The number of species caught by green traps was higher than by yellow and green traps (estimated marginal means, green: $2.67 \pm 0.49$, yellow-and-green: $1.73 \pm 0.44 ; F_{1,26.03}$ $=10.76, P=0.0029)$. The likely reason for higher species

Table 1. The weekly and total numbers of Vespula and Dolichovespula wasps caught by green and yellow and green banded beer traps $(N=15 \& 15)$ from the $7^{\text {th }}$ to the $28^{\text {th }}$ of August, 2016.

\begin{tabular}{|c|c|c|c|c|c|c|c|c|}
\hline \multirow{2}{*}{ Species } & \multicolumn{2}{|c|}{ Week 1} & \multicolumn{2}{|c|}{ Week 2} & \multicolumn{2}{|c|}{ Week 3} & \multicolumn{2}{|c|}{ Total } \\
\hline & green & yellow-green & green & yellow-green & green & yellow-green & green & yellow-green \\
\hline Vespula vulgaris & 46 & 42 & 115 & 118 & 140 & 95 & 301 & 255 \\
\hline Vespula rufa & 2 & 0 & 2 & 1 & 0 & 1 & 4 & 2 \\
\hline Dolichovespula media & 1 & 4 & 5 & 3 & 6 & 4 & 12 & 11 \\
\hline Dolichovespula saxonica & 3 & 0 & 5 & 3 & 6 & 0 & 14 & 3 \\
\hline Dolichovespula norvegica & 1 & 0 & 0 & 1 & 0 & 0 & 1 & 1 \\
\hline Dolichovespula sylvestris & 0 & 0 & 1 & 0 & 0 & 0 & 1 & 0 \\
\hline Total & 53 & 46 & 128 & 126 & 152 & 100 & 333 & 272 \\
\hline
\end{tabular}



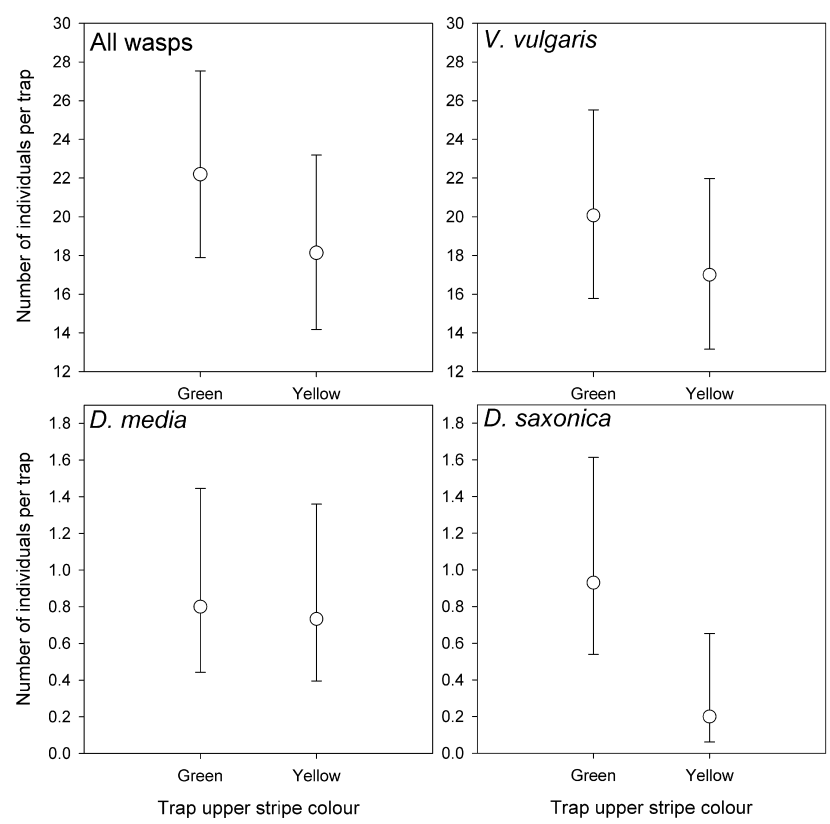

Fig. 3. The estimated marginal mean numbers of individuals caught per trap by green and yellow and green striped traps for all wasps and specifically for Vespula vulgaris, Dolichovespula media and $D$. saxonica. Estimated marginal means and asymmetric $95 \%$ confidence limits were modelled using generalized linear models with Poisson distribution.

richness in green traps is the green trap biased occurrence of $D$. saxonica.

The number of wasps varied similarly between the two types of traps during the three week period (interaction term trap type $\mathrm{X}$ week; Table 2). The total number of wasps and number of $V$. vulgaris wasps did not differ between trap types in the three different week long periods, but the number of wasps increased significantly during the three weeks (Table 2, Fig. 4). In both cases the increase was significant between the first and second week and the first and third week, but not between the second and third week. (Tukey's pairwise comparisons both in all wasps combined and in $V$. vulgaris were: 1 vs. $2: P<0.001$; 1 vs. $3: P<$ 0.001 ; and 2 vs. $3: P=0.99$.) For $D$. media and $D$. saxonica there were no significant differences between week long trapping periods; but for $D$. saxonica, there was a significant difference between trap types (Table 2).

\section{DISCUSSION}

Yellow and green traps were not especially attractive to the Vespula and Dolichovespula wasps. In fact, while colour did not have any significant role in the attractiveness of traps for the common wasp, $V$. vulgaris, and median wasp,
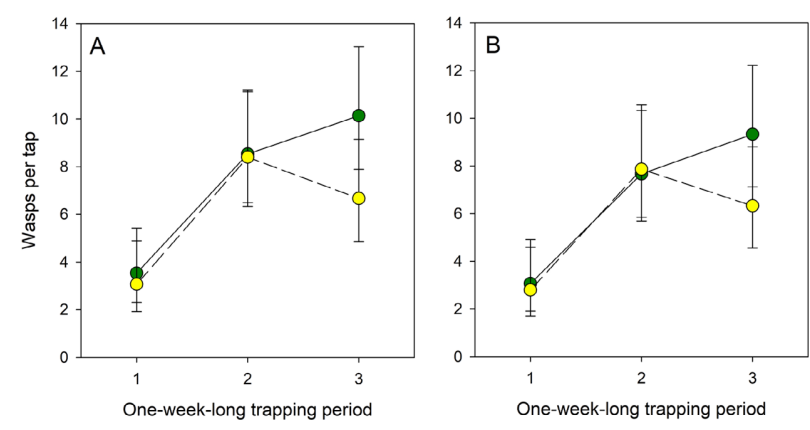

Fig. 4. Variation in numbers of wasps caught during the three trapping weeks $7^{\text {th }}-28^{\text {th }}$ August 2016 by green and yellow and green traps (green and yellow dots, respectively). A - all species; B Vespula vulgaris. Estimated marginal means and asymmetric $95 \%$ confidence limits were modelled using generalized linear models with Poisson distribution.

D. media, in the case of the Saxon wasp, D. saxonica, yellow and green traps were significantly less attractive than green traps. The number of $D$. saxonica specimens caught was only 17 , therefore, the difference between catches of the two types of traps could due to the effect of the small sample. However, while this cannot be excluded it may not be the case, as the $D$. saxonica specimens were welldistributed among pairs of traps and along transects, and were caught by 12 of 15 pairs of traps during the three week trapping period (Table 3). The reason for the possible preference of $D$. saxonica for green traps is unknown; and due to the low number of specimens caught in the present study, there needs to be further testing of this apparent preference in the future. Since the study area lacked wasps of the genus Vespa and Polistes, it is still possible that yellow could be an attractant for these wasps. However, Demichelis et al. (2014) does not report Vespa and Polistes being attracted to yellow.

The difference between the numbers of all the wasps and V. vulgaris, which made up over $90 \%$ of the total catch, caught in the first and second trapping periods, indicated an increase in the number of wasps over the sampling period. The numbers of $D$. media and $D$. saxonica caught were possibly too low for detecting any temporal trends.

The transparency of the traps may influence the results because wasps may be attracted by the presence of conspecific wasps as potential indicators of a resource (D'adamo $\&$ Lozada, 2005). In the present study, the numbers of $V$. vulgaris was significantly associated with particular pairs of traps. However, conspecific attraction seems to occur in some cases, as indicated by the high catches of some yellow and green traps (see Fig. 2), which overall caught fewer wasps than green traps (but not significantly).

Table 2. Results of the statistical tests using repeated linear mixed models for all species (Vespula vulgaris, Dolichovespula media and Dolichovespula saxonica). The interaction term Type $\times$ Period did not converge due to no specimens of $D$. saxonica being caught in periods 1 and 3 in yellow and green traps.

\begin{tabular}{lccc}
\hline Species & Type $\times$ Period & Type & Period \\
\hline All species & $F_{2,69.32}=1.36, P=0.26$ & $F_{1,71.41}=3.21, P=0.077$ & $F_{2,75.72}=17.36, P<0.0001$ \\
Vespula vulgaris & $F_{2,69.97}=1.31, P=0.28$ & $F_{1,71.87}=1.96, P=0.17$ & $F_{2,76.88}=16.29, P<0.0001$ \\
Dolichovespula media & $F_{2,72.98}=1.09, P=0.34$ & $F_{1,72.09}=0.05, P=0.83$ & $F_{2,73.71}=0.83, P=0.44$ \\
Dolichovespula saxonica & did not converge & $F_{1,83.81}=5.37, P=0.023$ & $F_{2,73.97}=0.95, P=0.39$ \\
\hline
\end{tabular}


Table 3. The numbers of Dolichovespula saxonica caught by the pairs of traps along the different transects.

\begin{tabular}{ccccc}
\hline \multirow{2}{*}{ Transect } & Trap pair & \multicolumn{3}{c}{ Number of D. saxonica } \\
\cline { 3 - 5 } & & Week 1 & Week 2 & Week 3 \\
\hline 1 & 1 & 0 & 0 & 1 \\
& 2 & 0 & 0 & 0 \\
& 3 & 0 & 2 & 1 \\
2 & 4 & 0 & 1 & 1 \\
& 5 & 0 & 2 & 0 \\
& 6 & 0 & 0 & 0 \\
& 7 & 0 & 0 & 0 \\
& 8 & 1 & 0 & 0 \\
& 9 & 0 & 0 & 1 \\
& 10 & 0 & 0 & 0 \\
& 11 & 1 & 1 & 0 \\
& 12 & 0 & 0 & 1 \\
& 13 & 0 & 2 & 1 \\
& 14 & 1 & 0 & 0 \\
& 15 & 0 & 0 & 0 \\
\hline
\end{tabular}

Yellow is known to attract many insect pests and pollinators (e.g. Smart et al., 1997; Hickman et al., 2001; Vesterlund et al., 2014). Thus yellow coloured wasp traps may attract more non target insects than neutral coloured traps. An alarming number of non-target insects are caught by these traps (Hallmann et al., 2017). Thus, when managing pest insect populations, it is important not to cause collateral damage to insects other than pests. Unfortunately, in this study the other insects caught were not collected and stored for later identification.

In this experiment, home-made traps rather than commercial traps were used, and they appeared as a brown mass (attractant liquid) with a strand of green and yellow above. Commercial traps are very different as some can be entirely yellow. Visual cues provided by our traps are not the same as those provided by commercial traps and therefore it is not possible to compare our results with those of studies using commercial traps.

In conclusion, based on the current results, while yellow may attract herbivorous insects, it doesn't attract wasps. Therefore, the rationale for using yellow traps to catch wasps may be questionable. For wasps, the bait itself may be a more important lure than the colour; thus, neutral coloured traps might be enough. Further studies are needed to verify the results in a wider geographic area, for different genera of social wasps such as Polistes and Vespa, and especially to monitor the risk to insects other than pests.

ACKNOWLEDGEMENTS. T. Eskelinen helped in the fieldwork. A. Perrard and an anonymous reviewer helped improve the manuscript. The English language of the manuscript was checked by a professional proof-reader of the company Lingsoft. JS carried out all phases of the study.

\section{REFERENCES}

Bacandritsos N., Papanastasiou I., Saitanis C. \& Roinioti E. 2006: Three non-toxic insect traps useful in trapping wasps enemies of honeybees. - Bull. Insectol. 59: 135-145.
Beggs J.R., Brockerhoff E.G., Corle J.C., Kenis M., Masciocchi M., Muller F., Rome Q. \& Villemant C. 2011: Ecological effects and management of invasive alien Vespidae. - BioControl 56: 505-526.

CHANG V. 1988: Toxic baiting of the western yellowjacket (Hymenoptera: Vespidae) in Hawaii. - J. Econ. Entomol. 81: 228-235.

D'ADAmo P. \& Lozada M. 2005: Conspecific and food attraction in the wasp Vespula germanica (Hymenoptera: Vespidae), and their possible contributions to control. - Ann. Entomol. Soc. Am. 98: 236-240.

Demichelis S., Manino A., Minuto G., Mariotti M. \& Porporato M. 2014: Social wasp trapping in north west Italy: comparison of different bait-traps and first detection of Vespa velutina. Bull. Insectol. 67: 307-317.

DvořÁK L. 2007: Social wasps (Hymenoptera: Vespidae) trapped with beer in European forest ecosystems. - Acta Mus. Morav. Sci. Biol. (Brno) 92: 181-204.

Dvoř́x L. \& Landolt P.J. 2006: Social wasps trapped in the Czech Republic with syrup and fermented fruit and comparison with similar studies (Hymenoptera: Vespidae). - Bull. Insectol. 59: 115-120.

Dvoř́́K L. \& RoBerTs S.P.M. 2006: Key to the paper and social wasps of Central Europe (Hymenoptera: Vespidae). - Acta Entomol. Mus. Nat. Pragae 46: 221-244.

Hallmann C.A., Sorg M., Jongejans E., Siepel H., Hofland N., Schwan H., Stenmans W., Müller A., Sumser H, Hörren T., Goulson D. \& DE KRoOn H. 2017: More than 75 percent decline over 27 years in total flying insect biomass in protected areas. - PLoS ONE 12(10): e0185809, 21 pp.

Hickman J.M., Wratten S.D., Jepson P.C. \& Frampton C.M. 2001: Effect of hunger on yellow water trap catches of hoverfly (Diptera: Syrphidae) adults. - Agric. For. Entomol. 3: 35-40.

Landolt P.J., Pantoja A. \& Green D. 2005: Yellowjacket wasps (Hymenoptera: Vespidae) trapped in Alaska with heptyl butyrate, acetic acid and isobutanol. - J. Entomol. Soc. British Columbia 102: 35-41.

Landolt P.J., Tóth M. \& Jósvai J. 2007: First European report of social wasps trapped in response to acetic acid, isobutanol, 2-methyl-2-propanol and heptyl butyrate in tests conducted in Hungary. - Bull. Insectol. 60: 7-11.

Rust M.K. \& Su N.-Y. 2012: Managing social insects of urban importance. - Annu. Rev. Entomol. 57: 355-375.

ShARP J.L. \& JAMES J. 1979: Color preference of Vespula squamosa. - Environ. Entomol. 8: 708-710.

Smart L.E., Blight M.M. \& Hick A.J. 1997: Effect of visual cues and a mixture of isothiocyanates on trap capture of cabbage seed weevil, Ceutorhynchus assimilis. $-J$. Chem. Ecol. 23: 889-902.

SORVARI J. 2013: Social wasp (Hymenoptera: Vespidae) beer trapping in Finland 2008-2012: a German surprise. - Entomol. Fenn. 24: 156-164.

Unelius C.R., El-Sayed A.M., Twidle A.M., Stinger L.D., ManNING L.M., Sullivan T.E.S., Brown R.L. \& Noble A.D.L. 2014: Volatiles from green-lipped mussel as a lead to vespid wasp attractants. - J. Appl. Entomol. 138: 87-95.

Vesterlund S.-R., Kakko M., VASEmägi A. \& Sorvari J. 2014: Status and monitoring of the buff-tailed bumblebee Bombus terrestris Linnaeus (Hymenoptera: Apidae) in Southern Finland. - Entomol. Fenn. 25: 49-56.

WitT R. 2009: Wespen. 2nd ed. Vademecum, Oldenburg, 400 pp. 